\section{Marcadores tumorales en la reagudización de la fibrosis pulmonar}

\section{Sr. Director:}

Está descrita la elevación de distintos marcadores tumorales en las reagudizaciones de la fibrosis pulmonar, principalmente del CA 19/9 y recientemente del 15/3 (1). Describimos un caso en el que se elevaron los marcadores tumorales antígeno carcinoembrionario (CEA), CA 125 y CA 19/9 de forma paralela al empeoramiento del curso clínico del paciente.

Varón de 70 años con neoplasia de colon intervenida hace 13 años en estadío T3, N1, M0 con quimioterapia posterior y seguimiento por Oncología mediante ecografía abdominal y colonoscopias anuales, poliartritis de reciente diagnóstico en brotes de predominio en cintura escapular con marcadores inmunológicos negativos salvo el factor reumatoide, fibrosis pulmonar diagnosticada mediante tomografía axial computerizada de alta resolución (TACAR) 4 meses antes, que ingresó en nuestro hospital por cuadro de fiebre, astenia, escalofríos y expectoración blanquecina de unos 4-5 días de evolución. Su tratamiento domiciliario consistía en prednisona, sulfasalazina, calcio y vit. D. Había sido dado de alta dos semanas antes de nuestro hospital por un cuadro de tos con expectoración blanquecina y disnea de mínimos esfuerzos con buena evolución. En la analítica de entonces destacaban: CEA: 2,6 ng/ml (VN: 0-3 ng/ml), CA 125: 68,7 U/ml $(\mathrm{VN}<35 \mathrm{U} / \mathrm{ml}), \mathrm{CA} 19 / 9: 152.7 \mathrm{U} / \mathrm{ml}(\mathrm{VN}<37$ $\mathrm{U} / \mathrm{ml})$, FR: $116 \mathrm{U} / \mathrm{ml}$ ( VN < $14 \mathrm{U} / \mathrm{ml})$. Tras permanecer dos días en Planta el paciente empeoró progresivamente con mayor disnea e insuficiencia respiratoria por lo que ingresó en UCI. En el hemogra-

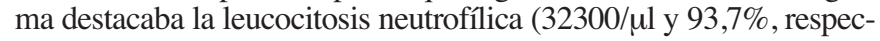
tivamente) y en la bioquímica: LDH: 17.737 U/l, GOT: $5.570 \mathrm{U} / \mathrm{l}$, GPT: $2.228 \mathrm{U} / \mathrm{l}, \mathrm{PCR}: 19,03 \mathrm{mg} / \mathrm{dl}$, lactato arterial: $9,4 \mathrm{mg} / \mathrm{dl}$. La radiografía de tórax mostró empeoramiento de su patrón intersticial previo. Con mascarilla de oxígeno con reservorio mantenía saturación arterial de oxígeno de $85 \%$ con $\mathrm{paO}_{2}$ de $48 \mathrm{mmHg}$ por lo que se pasó a aplicar ventilación mecánica no invasiva en modalidad BiPAP, consiguiendo mantener la saturación de oxígeno entre 90$94 \%$ con $\mathrm{paO}_{2}$ de $55-65 \mathrm{mmHg}$ con $\mathrm{FiO}_{2}$ del $55 \%$ y EPAP de $7 \mathrm{~cm}$ de $\mathrm{H}_{2} \mathrm{O}$. Se inició tratamiento con ceftazidima, levofloxacino, metilprednisolona, omeprazol, sedación con haloperidol y estabilización hemodinámica mediante aporte de fluidos e infusión de noradrenalina, que se pudo retirar a las 24 horas de su ingreso en UCI. En los días siguientes fue descendiendo la GOT, GPT, LDH y PCR hasta valores casi normales pero empeoró su situación respiratoria por lo que se intubó y conectó a ventilación mecánica. Se monitorizó el gasto cardiaco mediante termodilución transpulmonar y de forma continua mediante análisis del contorno del pulso con monitor PiC$\mathrm{CO}^{\circledR}$ (Pulsion Medical Systems) con catéter arterial femoral: gasto cardiaco de $8,7 \mathrm{l} / \mathrm{min}$ con resistencias vasculares sistémicas normales: 1.010 dynes. $\mathrm{sec} / \mathrm{cm}^{5}$, índice de volumen de sangre intratorácica (ITBVI): $2.211 \mathrm{ml} / \mathrm{m}^{2}$ (VN: $850-1.000 \mathrm{ml} / \mathrm{m}^{2}$ ) e índice de agua extravascular pulmonar de $26 \mathrm{ml} / \mathrm{kg}$ (VN: 3-7 ml/kg). Dados los valores de volemia aumentados se procedió primero a restricción hídrica y diuréticos y después se inició hemodiafiltración veno-venosa continua, con lo que a pesar de lograr valores de volemia cercanos a la normalidad los valores de agua extravascular pulmonar se mantuvieron elevados. Se aumentó la dosis de esteroide con tres bolos de $1 \mathrm{~g}$ de metilprednisolona/día sin mejorar la función pulmonar con hipercapnia progresiva y necesidad de $\mathrm{FiO} 2$ mayor del $60 \%$ sin respuesta a la PEEP. No se pudo realizar nueva TACAR por inestabilidad hemodinámica y respiratoria. Tanto la antigenemia en orina para neumococo y legionella, como serología para gérmenes atípicos, Mantoux, baciloscopias de esputo y cultivos de aspirado traqueal fueron negativos. En una analítica realizada a los 5 días de ingreso en UCI destacaban: FR: $180 \mathrm{U} / \mathrm{ml}(\mathrm{VN}<14 \mathrm{U} / \mathrm{ml}), \mathrm{IgG}: 1.490 \mathrm{mg} / \mathrm{dl}$ (VN: 690-1.400 mg/dl), C3: 36,2 mg/dl (VN:75-140 mg/dl), C4: 6,3 $\mathrm{mg} / \mathrm{dl}$ (10-34 mg/dl), CEA: 3,5 ng/ml (VN: 0-3), CA 125: 110,8 $\mathrm{U} / \mathrm{ml}(\mathrm{VN}<35 \mathrm{U} / \mathrm{ml}), \mathrm{CA}$ 19/9: 202,5 U/ml (VN < $37 \mathrm{U} / \mathrm{ml}) ;$ los anticuerpos antinucleares y los antineutrófilos negativos. El paciente no presentó mejoría gasométrica falleciendo tras 11 días de estancia en nuestra unidad.

Los tres marcadores tumorales, CEA, CA 125 y el CA 19/9 son glucoproteínas cuyos niveles plasmáticos pueden elevarse tanto en patología tumoral de distinta localización como en patologías benignas muy variadas. El CA 19/9 puede elevarse en la enfermedad intersticial pulmonar difusa, tanto en la fibrosis pulmonar idiopática como en la secundaria a colagenosis, asociándose su elevación a mal pronóstico (2). Además podría tener efecto quimiotáctico para los neutrófilos y sus niveles en el lavado broncoalveolar se correlacionan con otros marcadores de inflamación de la fibrosis pulmonar, como los cocientes factor de crecimiento del hepatocito/albúmina, elastasa/albúmina, LDH/albúmina y número de macrófagos alveolares y neutrófilos (3). Sin embargo, en otro trabajo se ha relacionado su aumento, más con el grado de fibrosis y destrucción pulmonar que con el grado de actividad de la enfermedad (4). No hemos encontrado ninguna referencia en la 
literatura que asocie la elevación del CA 125 con la reagudización de la fibrosis pulmonar idiopática o de enfermedades intersticiales difusas pulmonares.

Es posible, por lo tanto, que la monitorización de distintos marcadores tumorales puedan servir para evaluar la aceleración del curso clínico de enfermedades pulmonares intersticiales de distinto origen o detectar sus reagudizaciones y así valorar la realización de pruebas diagnósticas o modificaciones del tratamiento. En una reciente revisión no se citan estos marcadores en relación con reagudizaciones de la fibrosis pulmonar idiopática y sí la elastasa neutrofílica, LDH y KL-6 (5).

\section{J. Monterrubio Villar, A. Córdoba López}

Unidad de Medicina Intensiva. Hospital Comarcal Don BenitoVillanueva. Badajoz.
1. Altube Urrengoetxea L, Salinas Solano C, Aburto Barrenetxea M, Moraza Cortés FJ, Ballaz Quincoces A, Capelastegui Sainz A. Fase acelerada de la fibrosis pulmonar idiopática. Arch Bronconeumol 2007; 43: 516-8.

2. Kodama T, Satoh H, Ishikawa H, Ohtsuka M. Serum levels of CA 19-9 in patients with non-malignant respiratory diseases. J Clin Lab Anal 2007; 21: 103-6.

3. Obayashi Y, Fujita J, Nishyama T, Yoshinouchi T, Kamei T, Yamadori I, et al. Role of carbohy-drate sialyl Lewis (a) (CA 19-9) in bronchoalveolar lavage in patients with pulmonary fibrosis. Respiration 2000; 67: 146-52.

4. Shimizu Y, Hamada T, Tanaka Y, Sasaki A, Nemoto T. Colocalization of CA 19-9 and KL-6 to epithelial cells in dilated bronchioles in a patient with idiopathic pulmonary fibrosis complicated by diffuse alveolar damage. Respirology 2002; 7: 281-4.

5. Collard HR, Moore BB, Flaherty KR, Brown KK, Kaner RJ, King TE Jr, et al. Acute exacerba-tions of idiopathic pulmonary fibrosis. Am J Respir Crit Care Med 2007; 176: 636-43. 